\title{
The impurity of radioiodinated triolein
}

\author{
J. A. KENNEDY ${ }^{1}$ AND J. D. KINLOCH ${ }^{2}$ \\ From the Department of Medicine, Glasgow Royal Infirmary
}

SYNOPSIS Commercially supplied radioiodinated triolein has been shown by thin-layer chromat $\underline{\underline{\theta}}$ graphy and silicic acid column chromatography to contain impurities, consisting mainly of dig $\overrightarrow{5})_{-}$ cerides and monoglycerides, but also a small amount of free fatty acid. The effect of these impuritios on the radioiodinated triolein absorption test requires further investigation.

Radioiodinated fats and fatty acids have been used to investigate steathorrhoea since the method was first described by Stanley and Thannhauser in 1949. While undertaking an investigation of a case of steatorrhoea using ${ }^{131}$ I triolein, an inconsistency in the results was found. Although many potential sources of error in this test have been described (Cox, 1961), it was thought that our error might have been due to our faulty labelling of triolein with ${ }^{131}$ I by the method of Lubran and Pearson (1958). On analysis of our end product by thin-layer chromatography a considerable amount of impurity was found and the source was traced to the synthetic triolein supplied commercially; commercially supplied ${ }^{131}$ I triolein was found to contain similar impurities. Consequently more detailed studies of ${ }^{131}$ I triolein, as supplied commercially in carrier olive oil, were performed using silicic acid column chromatography.

\section{MATERIALS AND METHODS}

ANALYSIS OF ${ }^{131}$ I TRIOLEIN IN OLIVE OIL Synthetic triolein previously purified by distillation and crystallization at a low temperature was labelled with ${ }^{131}$ I by the technique of Lubran and Pearson (1958) at the Radiochemical Centre, Amersham. The radioiodinated triolein was then diluted with commercial olive oil, yielding the preparation which is in general use for malabsorption studies.

Thin-layer chromatography was carried out using silica gel as described by Mangold (1961). Autoradiograms were then prepared. Silicic acid column chromatography was carried out using the method of Horning, Williams, and Horning (1960). The percentage of the total radioactive load recovered in the eluate using different solvents was found and the main fractions present in each eluate identified (Table). In addition, infra-red spectrometry was carried out on the synthetic

\footnotetext{
'Present address: Department of Medicine, Graduate Hospital, University of Pennsylvania, Philadelphia, U.S.A.

2Present address: Department of Endocrine and Metabolic Diseases, Western General Hospital, Edinbu g', 4.

Received for publication 15 August 1963.
}

triolein, the ${ }^{131}$ I triolein in olive oil, and the separated fractions.

For comparison with the thin-layer chromatography $\frac{\text { of }}{\mathrm{f}_{\mathrm{f}}}$ the ${ }^{131}$ I triolein in olive oil, autoradiograms were atso prepared after chromatography of a mixture of the 13 triolein in olive oil and ${ }^{131}$ I oleic acid and of ${ }^{131} \mathrm{I}$ ole acid alone. Stained chromatoplates of non-radioactive oleic acid and triolein were also prepared and are shoven together with the autoradiograms as tracings in the diagram.

RESULTS

The autoradiogram (Fig. 1) of the chromatogram the ${ }^{131}$ I triolein in olive oil shows radioactive inpurities.

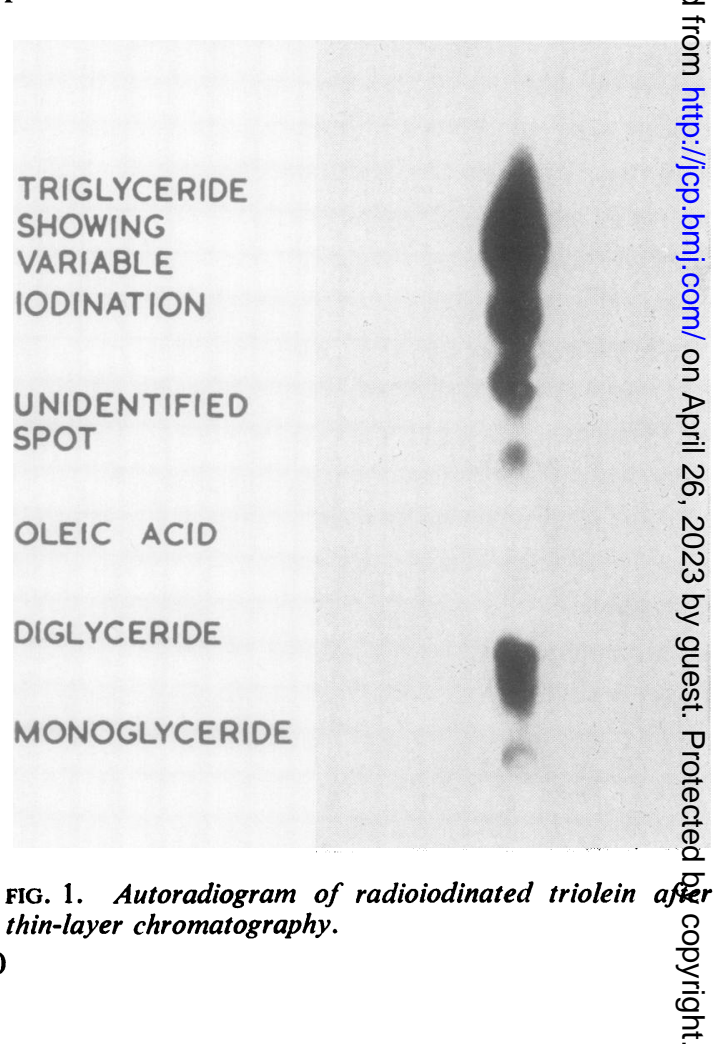


Tentative identification is suggested from the known migration values and from the partial resolution of the triglycerides into three spots because of the variation in the degree of iodination of the double bonds present in the fatty acid side chains. The main impurity is present as diglycerides and little radioactivity appears to occur in the free fatty acid. This finding was confirmed by the stained chromatoplate as is shown in the diagram (Fig. 2) of the superimposed tracings. The nature of the unidentified spot in the autoradiogram remains obscure. It was thought that it might be due to a triglyceride with a polyunsaturated side chain, but this was not confirmed by liquid gas chromatography. It did not appear in analyses of subsequent samples of triolein.

The results of radioanalysis of the column fractions are tabulated below.

$\begin{array}{ll}\text { Eluate Fraction } \quad \text { Predicted Output } & \begin{array}{l}\text { Percentage Total } \\ \text { Radioactivity Load in } \\ \text { Fractions }\end{array} \\ \end{array}$

\section{$60 \%$ Benzene in} hexane

$100 \%$ Benzene

$100 \%$ Methanol

Triglycerides

Free fatty acid

Diglycerides and

monoglycerides

Unrecovered

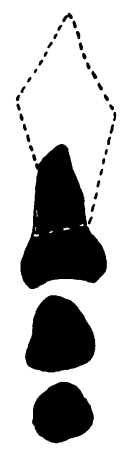

OLEIC

ACID

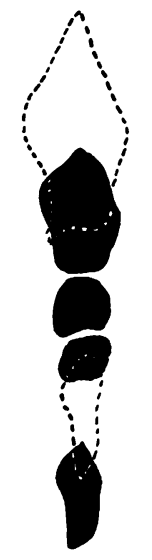

\section{$50 \cdot 2$}

$7 \cdot 2$

$29 \cdot 1$

13.5
Infra-red analysis failed to reveal the presence of lower glycerides in either synthetic triolein or in the ${ }^{131}$ I triolein in olive oil, although it verified the presence of lower glycerides in the methanol fraction of the silicic acid column. The reason for this finding is uncertain but it may be due to the insensitivity of infra-red spectrometry in this application.

\section{DISCUSSION}

About $30 \%$ of the total radioactivity of a commercial sample of ${ }^{131} \mathrm{I}$ triolein was found to be present in a diglyceride impurity; there was little radioactivity in the free fatty acid.

Mattson and Volpenheim (1962) have reviewed the methods of synthesizing glycerides and commented on the difficulties in preparing pure triolein, describing some of the impurities that result. Lakshminarayana, Kruger, Cornwell, and Brown (1960) have also noted impurities in ${ }^{131}$ I triolein, and found in their analysis that the methyl esters, monoglycerides, and diglycerides, present as impurities, appeared to take up the ${ }^{131}$ I label to a greater extent than might have been expected from chemical analysis.

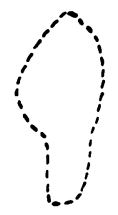

FIG. 2. Comparison of autoradiograms of radioiodinated preparations (shaded areas) and stained chromatoplates of unlabelled triolein and oleic acid (broken lines).

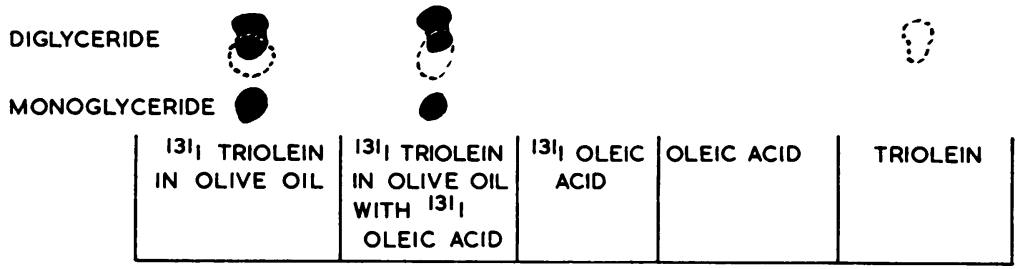


It would be of interest to know whether the lower glyceride impurity in the triolein has any effect on the ${ }^{131}$ I triolein absorption test and this is being investigated using a purified ${ }^{131} \mathrm{I}$ triolein for comparison.

We are grateful to Professor E. M. McGirr, Dr. J. H. Wright, Dr. J. Badenoch, and Dr. V. Lawrie for their advice and encouragement.

\section{REFERENCES}

Cox, A. G. (1961). Brit. med. J., 2, 933.

Horning, M. G., Williams, E. A., and Horning, E. C. (1960). J. Lipid Res., 1, 482.

Lakshminarayana, G., Kruger, F. A., Cornwell, D. G., and Brown, J. B. (1960). Arch. Biochem., 88, 318.
Lubran, M., and Pearson, J. D. (1958). J. clin. Path., 11, 165. Mangold, H. K. (1961). J. Amer. Oil Chem. Soc., 38, 708. Mattson, F. H., and Volpenheim, R. A. (1962). J. Lipid Res., 3, 28 Stanley, M. M., and Thannhauser, S. J. (1949). J. Lab. clin. Med., 34J 1634.

\section{ADDENDUM}

Since this paper was written, analysis of a purified triolein (99\% triglyceride) labelled with ${ }^{131}$ I at the Radiochemical Centre, Amersham, has revealed $16 \%$ lower glycerides and $4 \%$ oleic acid in the end product. This suggests that the mode of preparatior $\vec{w}$ (possibly heating to $60^{\circ} \mathrm{C}$. to evaporate solvent) mus? contribute to the impurities of ${ }^{131}$ I triolein.

\section{The January 1964 Issue}

\section{THE JANUARY 1964 ISSUE CONTAINS THE FOLLOWING PAPERS}

Coagulation and fibrinolysis in injured patients $D$. INNES and S. SEVITT

Investigations into the Euglena method for the assay of vitamin $B_{12}$ in serum BARBARA B. ANDERSON

The assay of folic-acid activity of liver MYRA C. BENNETT, VALERIE BERRY, I. CHANARIN, and S. ARDEMAN

The urinary excretion and tissue retention of cyanocobalamin by subjects given repeated parenteral doses J. F. ADAMS

Blood groups and diabetes mellitus A. L. MACAFEE

The ABO blood groups of carcinoma of the oesophagus and of benign prostatic hyperplasia $W$. H. BEASLEY

Rapid adhesive platelet count in whole blood ROBERT D. EASTHAM

The value of Jirgl's flocculation test in the diagnosis of jaundice JOYCE L. BELL and ROGER WILLIAMS

The diagnostic value of serum leucine aminopeptidase G. MERICAS, E. ANAGNOSTOU, ST. HADZIYANNIS, and S. KAKARI

Serum levels of creatine phosphokinase P. D. GRIFFITHS

A simple technique using 'dialysable' thyroxine for assessment of thyroid status T. M. D. GIMLETTE

Localization of leucine aminopeptidase isoenzymes B. W. MEADE and S. B. ROSALKI
Urinary excretion of metabolites of catecholamines in normal individuals and hypertensive patients $R$. J GEORGES and L. G. WHITBY

Antibiotic sensitivity of Proteus species MARY BARBEt and PAMELA M. WATERWORTH

An improved method of isolating salmonellae from? contaminated desiccated coconut J. B. IVESON, N $\overrightarrow{\vec{O}}$ KOVACS, and WM. LAURIE

Some aspects of nasal carriage of staphylococci w. c NOBLE, R. E. O. WILLIAMS, M. PATRICIA JEVONS, and R. A SHOOTER

A pitfall in the cytodiagnosis of sputum of asthmatic BERNARD NAYLOR and CONSTANTINE RAILEY

Gastro-duodenal Crohn's disease J. PRYSE-DAVIES

Obituary: Matthew Harris O'Connor

\section{Technical Methods}

A micromethod for estimating osmotic fragility of erythrocytes S. T. G. BUTTERWORTH

A simple method for the use of water melon seed preparations in the estimation of blood urea $K$. AN KHALEQUE, M. G. MUAZZAM, and P. ISPAHANI

Liquid nitrogen storage of haemoglobin variants R. HUNTSMAN, B. A. L. HURN, J. LIDDELL, H. LEHMANN, an कृ P. K. SUKUMARAN

A simple control system for $\mathrm{CO}_{2}$ incubators WRIGHT

Book reviews

Copies are still available and may be obtained from the PUBLISHING MANAGER, BRITISH MEDICAL ASSOCIATION. TAVISTOCK SQUARE, W.C.I., price 18s. 6D. 